\title{
cDNA-AFLP analysis of Psidium guajava L. cultivars under water stress and mechanical injury: methodological implications
}

\author{
Cláudia Maria Furlan ${ }^{1 *}$, Samantha Zanotta ${ }^{1}$, Antonio Salatino \\ ${ }^{1}$ Department of Botany, Bioscience Institute, University of São Paulo, São Paulo, SP, Brazil. \\ *Corresponding author: furlancm@yahoo.com.br \\ Received: 10 January 2012; Accepted 20 June 2012
}

\begin{abstract}
Studies involving amplified fragment length polymorphism (CDNA-AFLP) have often used polyacrylamide gels with radiolabeled primers in order to establish best primer combinations, to analyze, and to recover transcript-derived fragments. Use of automatic sequencer to establish best primer combinations is convenient, because it saves time, reduces costs and risks of contamination with radioactive material and acrylamide, and allows objective band-matching and more precise evaluation of transcript-derived fragments intensities. This study aimed at examining the gene expression of commercial cultivars of $P$. guajava subjected to water and mechanical injury stresses, combining analyses by automatic sequencer and fluorescent kits for polyacrylamide gel electrophoresis. Firstly, 64 combinations of EcoRI and Msel primers were tested. Ten combinations with higher number of polymorphic fragments were then selected for transcript-derived fragments recovering and cluster analysis, involving 45 saplings of $P$. guajava. Two groups were obtained, one composed by the control samplings, and another formed by samplings undergoing stress, with no clear distinction between stress treatments. The results revealed the convenience of using a combination of automatic sequencer and fluorescent kits for polyacrylamide gel electrophoreses to examine gene expression profiles. The Unweighted Pair Group Method with Arithmetic Mean analysis using Euclidean distances points out a similar induced response mechanism of $P$. guajava undergoing water stress and mechanical injury.
\end{abstract}

Keywords: automatic sequencer, gene expression, mechanical injury, water stress.

\section{INTRODUCTION}

Plants are normally exposed to biotic and abiotic stresses, such as drought, low nutrient availability, air pollutants, and attack by pathogens and herbivores. Interactions of different stress factors usually result in synergism, affecting biochemical and physiological processes, which influence the plant growth and development (Távora et al., 2001). Harmful effects derived from global climate changes possibly impart losses in crop productivity (Davison and Cape, 2003;
Grünhage and Jager, 2003; Krupa, 2003). Studies aiming at detecting gene expression induced by stress factors may help evaluating the degrees of susceptibility of commercial cultivars, minimizing losses in productivity.

Techniques for gene expression analyses in plants have been widely explored (Kuhn, 2001). Bachem et al. $(1996 ; 1998)$ developed the technique cDNA-AFLP for gene expression analysis, which is based on cDNA attainment of the expressed 
gene, its digestion by restriction enzymes and further amplification of restriction fragments. The main advantage of cDNA-AFLP is the possibility of amplifying a limited number of fragments, due to the primers selectivity (Reijans et al., 2003). Among other advantages are the possibilities of detecting low-abundance mRNAs and comparing directly band intensities between samples (Schirmer et al., 2010).

CDNA-AFLP traditionally uses polyacrylamide gel with radiolabeled primers to test best primer combinations, analyze and recover transcript-derived fragments (TDFs). TDF polymorphisms are evaluated visually on the autoradiograms or with the help of scanners. The present work has proposed the use of automatic sequencer at the beginning of cDNA-AFLP analysis, in order to select the best primer combinations. Afterwards, polyacrylamide gel electrophoreses should be used to recover differentially expressed transcripts. This integrated strategy allows testing higher numbers of primer combinations and reduces exposure to radioactive material and acrylamide. In addition, it saves time, reduces the analyses costs and does not entail the often highly subjective visual analysis of gel electropherograms to select primer combinations.

Psidium guajava L. (guava, Myrtaceae) is cultivated in South and Central Americas, in Africa and in Asia for consumption of fruits in natura or commercial production of jams, ice creams, beverages, juices, syrups, and fruit pulp. Major guava producers are India, Mexico, Brazil, and Malaysia (Frutiseries, 2001). Brazil produces yearly about 300,000 tons of guava fruits from the cultivars Paluma, Pedro Santo, and Sassaoca; among them only plants of Paluma have been classified as tolerant to water deficiency (IBGE, 2010; Barbosa et al., 2003).

The knowledge on how some cultures respond to water or mechanical stress is crucial to understand hidden costs, with potentially ecological and agronomic implications. Drought stress causes substantially yield losses related to water-use efficiency, resulting on productivity losses too. Herbivory can affect plantcarbon gain directly, since part of the photosynthetic leaf tissue is removed. Indirectly, mechanical stress can also affect gas exchange and transport of nutrient and water. According to Aldea et al. (2005), increases on transpiration rate from the cut edges are frequently observed, however the mechanism underlying the indirect effects of leaf damage are not well-understood and may vary for different plant species.

The present study aimed at analyzing the gene expression profiles of young individuals of three commercial cultivars of $P$. guajava, which were undergoing water stress and mechanical injury (removal of $50 \%$ of leaf area), combining techniques of analyses by polyacrylamide gel electrophoreses and automatic sequencer. The possibility to describe amounts of expressed sequence information (i.e., protein coding) in nonmodel organisms offers the chance to detect molecular variation of genes and to observe the species polymorphisms in natural environments.

\section{MATERIALS AND METHODS}

Fifteen saplings of $P$. guajava CV. Paluma, Pedro Sato and Sassaoca were obtained from Agromillora Taperão Ltda., a Brazilian producer specializing in shoot production by rooting semi-herbaceous guava cuttings. They were obtained with $200 \mathrm{~mm}$ tall on average, were transplanted to 2-L plastic pots, and filled with ground coconut fiber as substrate. After transplanting, saplings were kept in a greenhouse for a period of 60 days of acclimation. Lighting conditions, temperature and relative humidity were measured throughout the experimental period by an automatic recorder (HOBO). After the acclimation period, five saplings of each cultivar were kept in appropriate conditions of water supply, trying to avoid the attack of herbivores, and constituting the control treatment.

Five saplings of each cultivar were kept 15 days without water supply. After this period, the pair leaves of the third node (counting from top to bottom) were collected, frozen in liquid nitrogen, and stored $\left(-80^{\circ} \mathrm{C}\right)$ for further analyses.

For mechanical injury, another five saplings of each cultivar were used. A total of $50 \%$ of the leaves area from the third node was removed and, one hour after the mechanical injury, the remaining half leaf was collected, frozen in liquid nitrogen and stored at $-80^{\circ} \mathrm{C}$.

cDNA-AFLP: For RNA extraction, $100 \mathrm{mg}$ of plant material were ground in liquid nitrogen and extracted according to Salzman et al. (1999) with modifications. 
Quality and integrity of RNA were evaluated by spectrophotometry $\left(A_{260} / A_{280}\right)$ and $1.5 \%$ agarose electrophoresis gel.

cDNA was synthesized from $500 \mathrm{ng}$ of total RNA using SuperScript ${ }^{\text {Tw }}$ First-Strand Synthesis System (Invitrogen Life Technologies), according to manufacturer's specifications, and ds cDNA was obtained, according to Bachem et al. (1998).

cDNA-AFLP was performed from $300 \mathrm{ng}$ of CDNA using an Applied Biosystems kit for (plant regular genome), according to manufacturer's specifications. The fragments amplified by the tested primer combinations were analyzed using size standards (ROX) by ABIPrism 310 sequencer (Applied Biosystems).

The primer combinations providing higher numbers of polymorphic fragments were used for cluster analysis. The same combinations were used for fragment recovery and sequence, using a $6 \%$ polyacrylamide descendent electrophoresis gel.

Polyacrylamide gel was stained using silver nitrate (Creste et al., 2001). Bands were isolated from the gel and incubated at $37^{\circ} \mathrm{C}$ overnight using two volumes of ultrapure sterile water for each volume of gel cut. An aliquot of purified TDF (GFX purification kit, GE Healthcare) recovered was used as template for PCR amplification, using the same primer combination and subsequent sequencing.

Data analyses: Results obtained were analyzed by the ABIPrism Genescan software (Applied Biosystems). Control and stress treatments were compared by presence or absence and intensity of the fragments using ABIPrism Genotype software (Applied Biosystems). Tables generated by Genotyper were exported to Phylogenetic Analysis Using Parsimony (PAUP) software for cluster analyses (UPGMA, Euclidean distance).

\section{RESULTS}

cDNA-AFLP analysis by automatic sequencer allowed testing $64 \mathrm{EcoRI}$ and Msel primer combinations. Ten among these combinations were selected for recover and cluster analysis of the TDFs, which provided higher number of fragment length polymorphisms. Primer combinations tested and corresponding mean number of fragments obtained are shown in Table 1.

Table 1. List of primers tested for $P$. guajava cultivars (regular plant genome - Applied Biosystems) and number of amplified fragment length polymorphism obtained.

\begin{tabular}{|c|c|c|c|c|c|c|c|c|}
\hline EcoRI Msel & CAA & CAC & CAG & CAT & CTA & CTC & CTG & CTT \\
\hline AAC & 59 & 50 & $\varnothing$ & $\varnothing$ & $\varnothing$ & 10 & 8 & 80 \\
\hline AAG & 100 & 100 & $\emptyset$ & $\emptyset$ & $\varnothing$ & 75 & 70 & 14 \\
\hline ACA & 29 & 50 & 80 & 52 & 110 & 90 & 32 & $\varnothing$ \\
\hline ACC & 15 & 7 & 30 & 120 & 90 & $\varnothing$ & 10 & 12 \\
\hline ACG & $\varnothing$ & 10 & 15 & 80 & 100 & 27 & $\varnothing$ & $\varnothing$ \\
\hline ACT & 9 & $\varnothing$ & 60 & $\varnothing$ & 40 & 80 & 19 & 6 \\
\hline AGC & $\varnothing$ & 60 & $\varnothing$ & $\varnothing$ & $\varnothing$ & 20 & 20 & $\varnothing$ \\
\hline AGG & 90 & 5 & $\varnothing$ & $\varnothing$ & $\varnothing$ & $\emptyset$ & 70 & 80 \\
\hline
\end{tabular}

$\emptyset$ : primers combination resulting in less than five fragments; preamplification primers: $E c 0+3^{\prime} \mathrm{A}$ and $M s e+3^{\prime} \mathrm{C}$. Nitrogenous base: A: adenine; C: cytosine; G: guanine; T: thymine.

Electropherograms obtained with the automatic sequencer revealed different expression profiles between treatments. The expression profile obtained using the combination AAG/CAC is seen in Figure 1. Distinct band patterns were observed for the three cultivars studied, comparing control plants and those under stress treatments, indicating different gene expression patterns. These bands, or TDFs, were polymorphic, as much as they varied in intensity or were not detected in some samples. Some bands, particularly in the range from 120 to $140 \mathrm{bp}$, were more intense in both stress treatments in comparison with the respective controls.

Results of Unweighted Pair Group Method with Arithmetic Mean (UPGMA) cluster analysis of the amplified fragments obtained with the ten selected primers are shown in Figure 2. Two distinct clusters are discerned; one combining control samplings and other combining samplings subjected to the stress treatments of either low water availability or mechanical injury.

So far, 36 TDFs were excised from polyacrylamide gel electrophoresis and 9 were successfully amplified and sequenced. After basic local alignment search tool (BLAST) homology with GenBank deposited sequences was found for seven TDFs, which were present only in stress treatments. Among the seven TDFs, an Arabdopsis putative protein kinase and a probable phenylalanine ammonia-lyase from Barley presented a very good match. 

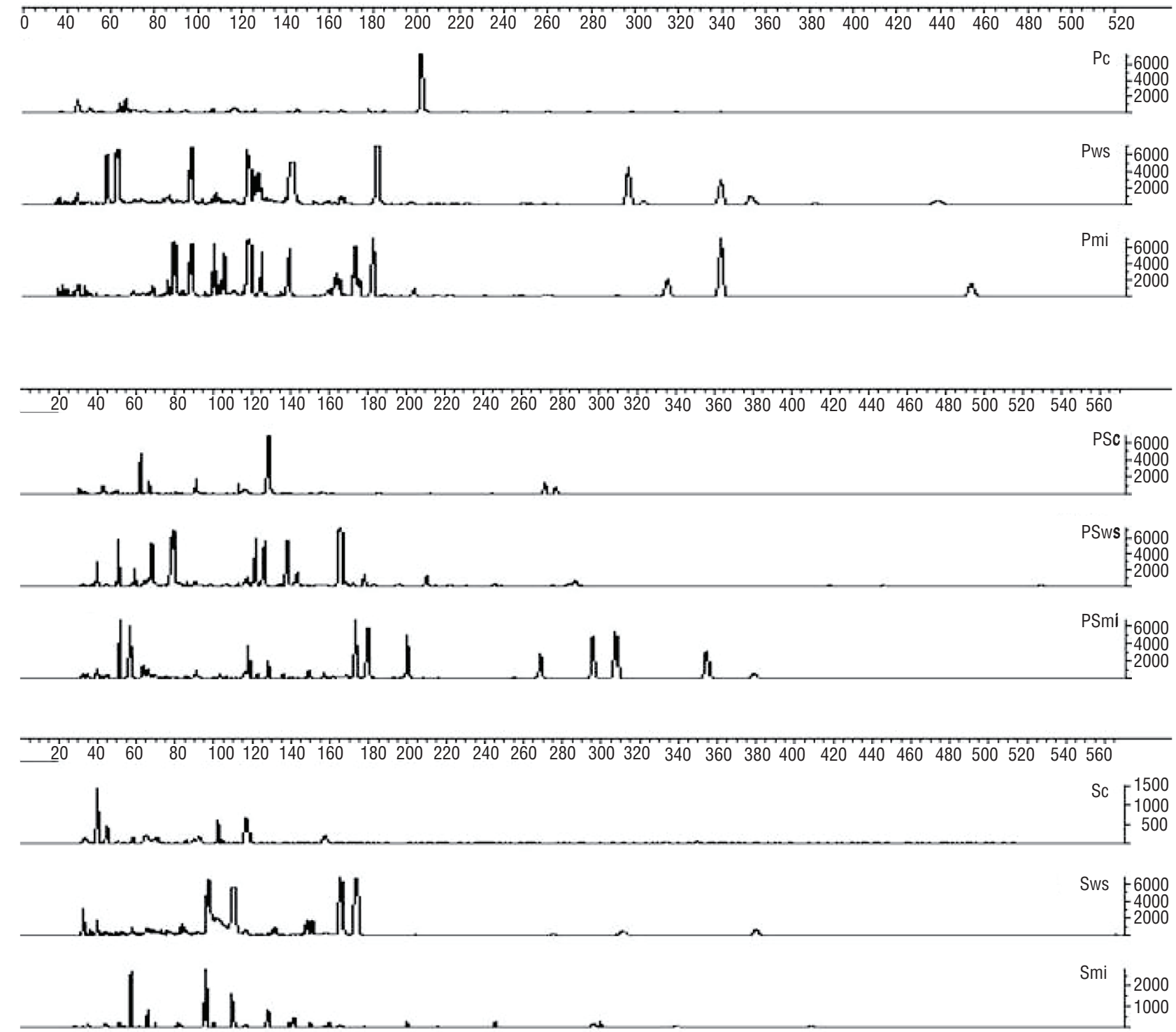

Figure 1. Expression profile using the primer combination AAG/CAC. P. guajava cultivars under control condition (c), water stress (ws), and mechanical injury (mi). The following cultivars were used: P: Paluma; PS: Pedro Sato; S: Sassaoca. Horizontal bar shows fragment length; vertical bar shows fragment abundance.

\section{DISCUSSION}

One of the goals in functional genomics and proteomics is to obtain expression profiles, allowing the detection of transcriptional changes in response to stress conditions. The cDNA-AFLP provides the expression profile of whole genomes, allowing the monitoring of transcriptional changes related to cellular development and/or environmental modifications (Levterova et al., 2010). The advantage of not requiring previous genome knowledge makes this technique a powerful tool for identifying novel genes in nonmodel organisms. In addition, CDNA-AFLP has high sensitivity and specificity, comparable to microarrays (Levterova et al., 2010).

Traditionally, studies using cDNA-AFLP apply radioactively labeled primers or silver staining polyacrylamide gel for transcription profile analysis (Vos et al., 1995; Cracium et al., 2006; Wang and Bughrara, 2007; Zhang et al., 2010). According to Dresler-Nurmi et al. (2000), fluorescence is an alternative to radioactive labeling since both methods provide comparable 
Euclidean distance

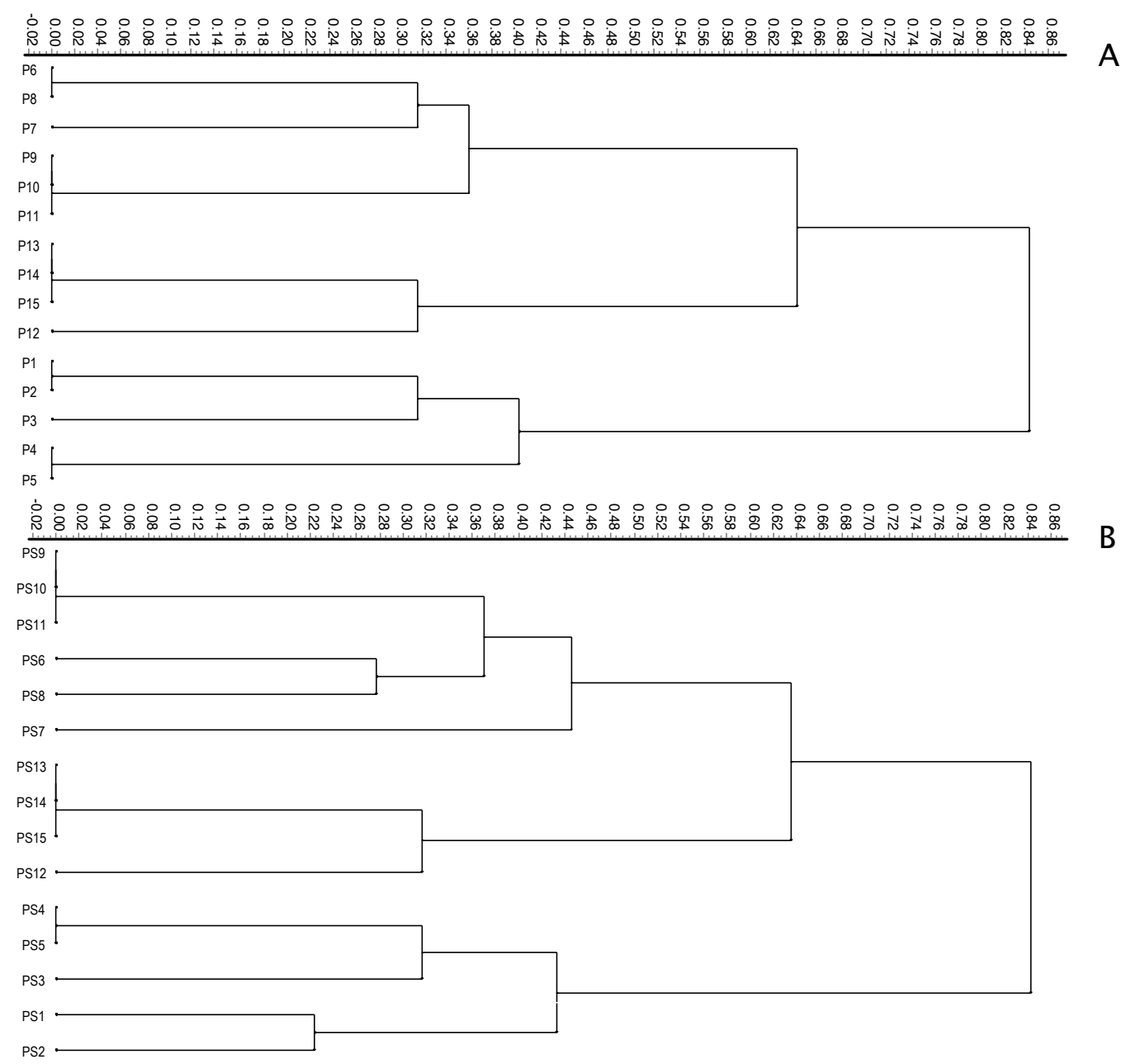

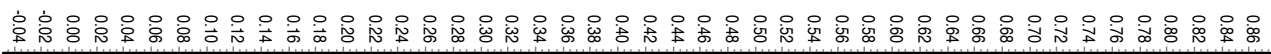

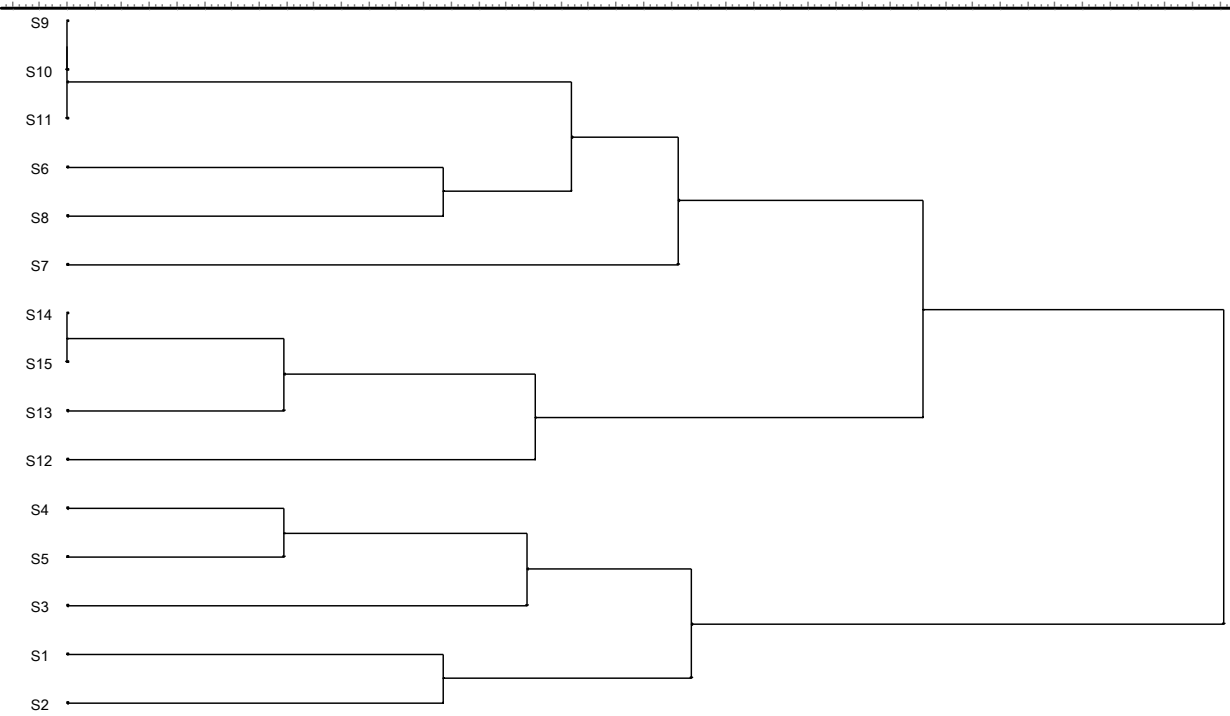

Figure 2. Cluster analysis (Unweighted Pair Group Method with Arithmetic Mean - UPGMA) using Euclidean distances as coefficient. P. guajava cultivars: A: Paluma; B: Pedro Sato; and C: Sassaoca. 1-5 correspond to control; 6-10 correspond to water stress, and 11-15 correspond to mechanical injury. 
results. Moreover, autoradiography can be hazardous and needs special laboratorial facilities (Dresler-Nurmi et al., 2000; Guo et al., 2006).

Using an automatic sequencer at the beginning of cDNA-AFLP, with the aim of identifying the best primer combinations, seemed to be an interesting strategy since it: takes less time to select primer combinations; reduces contact of the researcher with radioactive material and acrylamide; lowers the analysis cost; overcomes the inaccuracy of the gel visual analysis; allows more precise analysis of TDFs intensity; and enables the preparation of smaller numbers of polyacrylamide gel electrophoresis.

According to Korpelainen and Kostamo (2010), if several selective primers are used, a greater number of differentially expressed TDFs will be detected. The methodological strategy used in this work allowed testing a higher number of primer combinations. This factor could be interesting to enhance the number of the sequenced TDFs. Despite the small number of TDFs analyzed in this work, the results prove that the methodology is valuable to recover and sequence TDFs.

Several studies have demonstrated the effectiveness of cDNA-AFLP to analyze gene expression. Aoki et al. (2005) used cDNA-AFLP to study the response of salt stress in Glycine max. The authors identified 107 genes that were expressed differently after 72 hours of treatment with $100 \mathrm{mM} \mathrm{NaCl}$. Li et al. (2006) investigated the gene expression of different tomato genotypes infected by Oidium neolycopersici, and they found that $34 \%$ of the detected fragments exhibited homology with genes involved in plant defense mechanisms, $11 \%$ were signal transduction genes, $24 \%$ regulated genes, $11 \%$ synthesis and degradation of protein, and $12 \%$ genes were involved in energy metabolism, including photosynthesis and respiration related genes.

Bernardi et al. (2010) studied gene expression during Citrus sinensis ripening using cDNA-AFLP and subtracted suppression subtractive hybridization (SSH). Of the 301 probes founded, 20 corresponded to different transcripts, indicating differential expression in stage-to-stage and/or cultivar-to-cultivar comparisons. Transcripts encoding for anthocyanin biosynthesis predominated among the total overexpressed probes and the remaining differentially expressed transcripts were functionally associated with primary metabolism, flavor biosynthesis, defense, and signal transduction.

Herbivory disrupts the integrity of leaves resulting in a possible uncontrolled water-loss from cut edges. In this study, $50 \%$ of the leaf area was removed (mechanical injury), which could result in an increased rate of water-loss. Results from cDNA-AFLP showed similar gene expression profile between water and mechanical stress. Fragments (between 120 and 140 bp) with higher abundance appeared in both stress treatments, suggesting a possible common defense mechanism activated by water stress and mechanical injury. Cluster analyses pointed out the same result, different expression profile between stress treatments and control (Figure 2).

Sequencing TDFs between 120 and $140 \mathrm{bp}$, which were intensified during stress treatments, may allow a better understanding about the expression profiles of a tropical species during water deficiency and/or mechanical injury. So far, 36 TDFs were excised and 9 were successfully amplified and sequenced. After BLAST-search, homology with GenBank deposited sequences was found for seven TDFs, which were observed only under stress conditions.

Among the seven TDFs, an Arabdopsis putative protein kinase and a probable phenylalanine ammonialyase (PAL) from Barley presented a very good match with deposited sequences. In the first case, protein kinases are essential to the perception process of environmental factors, triggering signaling cascades under stress conditions. Kido et al. (2011), using SuperSAGE method, were able to identify 1,350 kinase candidates when considering only biotic libraries and 2,268, when regarding abiotic libraries. Authors also mentioned that additional searches in kinase specific databases were performed and allowed the identification of a relatively low number of additional kinases, which shows the lack of kinase databases for nonmodel organisms.

PAL is a key enzyme of shikimate pathway, responsible for the synthesis of a large number of phenolic compounds. According to Sánchez-Rodriguez et al. (2011), tolerance to biotic and abiotic stress in plants is often regulated by the metabolism of phenolic compounds, which generally are synthesized by the shikimate pathway. An important enzyme in this pathway is PAL, which catalyzes the nonoxidative deamination of L-phenylalanine to form trans-cinnamic acid, precursor of a large number of plant phenolic compounds, such as flavonoids, coumarins, lignins, and tannins. Increases in PAL activity and in other enzymes of the phenylpropanoid pathway in tomato and lettuce plants are common responses to different types of environmental stress, so it suggests the importance of those compounds on the plant stress response mechanism. 
Phenolic compounds are strongly active as antioxidants due to the high reactivity of the phenolic hydroxyl groups. Such reactivity may act as an antioxidant defense, inactivating reactive oxygen species (ROS) during an oxidative stress, such as the presence of air pollutants or water deficiency. Recently, flavonols have been additionally reported to be capable of regulating key developmental processes in eukaryotic cells faced with environmental-induced changes in cellular redox homeostasis (Williams et al., 2004; Peer and Murphy, 2007). Oh et al. (2010), observed accumulation of phenolic compounds in lettuce and have demonstrated that an increase in the phenolic concentration, as well as in PAL, could be correlated with better drought resistance.

The combination of cDNA-AFLP, using an automatic sequencer and fluorescent kits, with polyacrylamide gel electrophoresis, was shown to have high potential as an integrated strategy for gene expression analysis. It accelerates the choice of best primer combinations; allows cluster analysis of expression profiles prior to gene identification; and allows recuperating and sequencing TDFs. Using this combination of methods in the analysis of three $P$. guajava commercial cultivars, it was possible to verify different expression profiles induced by water stress and mechanical injury. Cluster analysis points out to a similar induced response mechanism of $P$. guajava under water stress and mechanical injury. Among recovered and sequenced TDFs, high homology of sequences was obtained to a putative protein kinase and PAL, both described as important in the plant response mechanism to biotic and abiotic stresses.

Acknowledgements: This research was supported by São Paulo Research Foundation (FAPESP) numbers 04/09665-6; 04/09972-6; 06/04765-8. AS is a fellow researcher of the Brazilian National Council of Technological and Scientific Development (CNPq).

\section{REFERENCES}

Aldea M, Hamilton JG, Resti JP, Zangerl AR, Berenbaum MR, Delucia E (2005) Indirect effects of insect herbivory on leaf gas exchange in soybean. Plant Cell Environ. 28:402-411.

Aoki A, Kanegami A, Mihara M, Kojima T, Shiraiwa M, Takahara $H$ (2005) Molecular cloning and characterization of a novel soybean gene encoding a leucine-zipper-like protein induced to salt stress. Gene 356:135-145.

Bachem CWB, der Hoeven RS, Bruijn SM, Vreugdenhil D, Zabeau M, Visser RGF (1996) Visualization of differential gene expression using a novel method of RNA fingerprinting based on AFLP: analysis of gene expression during potato tuber development. Plant J. 9:745-753.
Bachem CWB, Oomen RJFJ, Visser RGF (1998) Transcript imaging with CDNA-AFLP: a setep-by-step protocol. Plant Mol. Biol. Rep. 16:157-173.

Barbosa FB, Kiill LHP, Souza EA, Moreira WA, Alencar JA, Haji FNP (2003) Nível de dano, plantas invasoras hospedeiras, inimigos naturais e controle do psilídeo da goiabeira (Triozoida sp.) no submédio São Francisco. Rev. Bras. Frutic. 25:425-428.

Bernardi J, Licciardello C, Russo MP, Chiusano ML, Carletti G, Recupero R, Marocco A (2010) Use of a custom array to study differentially expressed genes during blood Orange (Citrus sinensis L. Osbeck) ripening. J. Plant Physiol. 167:301-310.

Craciun AR, Courbot M, Bourgis F, Salis P, Saumitou-Laprade P, Verbruggen N (2006) Comparative CDNA-AFLP analysis of Cd-tolerant and -sensitive genotypes derived from crosses between the $\mathrm{Cd}$ hyperaccumulator Arabidopsis halleri and Arabidopsis lyrata ssp. petraea. J. Exp. Bot. 57:2967-2983.

Creste S, Tulmann Neto A, Figueira A (2001) Detection of single sequence repeat polymorphism in denaturing polyacrylamide sequencing by silver staining. Plant Molecular Reporter 19:299-306.

Davison AW, Cape JN (2003) Atmospheric nitrogen compounds - issues related to agricultural systems. Environ. Int. 29:181-187.

Dresler-Nurmi A, Terefework Z, Kaijalainen S, Lindstrom K, Hatakka A (2000) Silver stained polyacrylamide gels and fluorescence-based automated capillary electrophoresis for detection of amplified fragment length polymorphism patterns obtained from white-rot fungi in the genus Trametes. J. Microbiol. Meth. 41:161-172.

Grünhage L, Jäger HJ (2003) From critical levels to critical loads for ozone: a discussion of a new experimental and modeling approach for establishing flux-response relationships for agricultural crops and native plant species. Environ. Pollut. 125:99-110.

Guo JR, Schnieder F, Verreet JA (2006) Differences between the fingerprints generated from total RNA and poly-A RNA using a modified procedure of cDNA-AFLP and silver staining. Biotechnol. Lett. 28:267-270.

IBGE. Goiabrás. 2010. Disponível em: http://www.ibge.gov.br/home/ presidencia/noticias. Acesso em: Junho de 2010.

Kido EA, Barbosa PKD, Neto JRCF, Pandolfi V, Houllou-Kido LM, Crovella S, Molina C, Kahl G, Benko-Iseppon AM (2011) Identification of Plant Protein Kinases in Response to Abiotic and Biotic Stresses using SuperSAGE. Curr. Protein. Pept. Sci. 12:643-656.

Korpelainen H, Kostamo K (2010) An improved and cost-effective cDNAAFLP method to investigate transcription-derived products when high throughput sequencing is not available. J. Biotechnol. 145:43-46.

Krupa SV (2003) Atmosphere and agriculture in the new millennium. Environ. Pollut. 126:293-300.

Kuhn E (2001) From library screening to microarray technology: strategies to determine gene expression profiles and to identify differentially regulated genes in plants. Ann. Bot. 87:139-155.

Levterova V, Panaiotov S, Brankova N, Tankova K (2010) Typing of genetic markers involved in stress response by fluorscent cDNA-Amplified fragment length polymorphism technique. Mol. Biotechnol. 45:34-38.

Li C, Yuling B, Jacobsen E, Visser R, Lindhout P, Bonnema G (2006) Tomato defense to the powdery mildew fungus: differences in expression of genes in susceptible, monogenic and polygenic resistance response are mainly in timing. Plant Mol. Biol.62:127-140.

Ministério da Integração Nacional. Frutiséries 1. Pernambuco - Goiaba. Brasília, maio de 2001. Disponível em: <http://www.mi.gov.br/infraestruturahidrica/publicacoes/frutiseries.asp>. Acesso em: 10 jul. 2012. 
Oh MM, Carey EE, Rajashekar CB (2010) Regulated water deficits improve phytochemical concentration in lettuce. J. Am. Soc. Hortic Sci. 135:223-229.

Peer WA, Murphy AS (2007) Flavonoids and auxin transport: modulators or regulators? Trends Plant Sci. 12:556-563.

Reijans M, Lascaris R, Groeneger A0, Wittenberg A, Wesselink E, Oeveren J, Wit E, Boorsma A, Voetdijk B, Spek H, Grivell LA, Simons G (2003) Quantitative comparison of cDNA-AFLP, microarrays, and genechip expression data in Saccharomyces cerevisiae. Genomics 82:606-618.

Salzman RA, Fujita T, Zhu-Salzman K, Hasegawa PM, Bressan RA (1999) An improved RNA isolation method for plant tissues containing high levels of phenolic compounds or carbohydrates. Plant. Molr. Biol. Rep. 17:11-17.

Sánchez-Rodriguez E, Ruiz JM, Ferreres F, Moreno D.A. (2011) Phenolic Metabolism in Grafted versus Nongrafted Cherry Tomatoes under the Influence of Water Stress. J. Agric. Food Chem. 59:8839-8846.
Schirmer K, Fischer BB, Madueira DJ, Pillai S (2010) Transcriptomics in ecotoxicology. Anal. Bioanal. Chem. 397:917-923.

Távora FJAF, Ferreira RG, Hernandez FFF (2001) Crescimento e relações hídricas em plantas de goiabeira submetidas a estresse salino com $\mathrm{NaCl}$. Rev. Bras. Frutic. 23:441-446.

Vos P, Hogers R, Bleeker M, Reijans M, van de Lee T, Hornes M, Frijters A, Pot J, Peleman J, Kuiper M, Zabeau M (1995) AFLP: a new concept for DNA fingerprinting. Nucleic Acids Res. 23:285-292.

Wang JP, Bughrara SS (2007) Monitoring of gene expression profiles and identification of candidate genes involved in drought responses in Festuca mairei. Mol. Genet. Genomics 277:571-587.

Williams RJ, Spencer JPE, Rice-Evans CA (2004) Flavonoids: antioxidants or signaling molecules. Free Radical Bio. Med. 36:838-849.

Zhang D, Liu B, Zhao C, Lu X, Wan D, Ma F, Chen L, Liu J (2010) Ecological functions and differentially expressed transcripts of translucent bracts in an alpine 'glasshouse' plant Rheum nobile (Polygonaceae). Planta 231:1505-1511. 